\title{
Uma nova espécie de Coussarea Aubl. (Rubiaceae) para a Mata Atlântica no Estado da Bahia, Brasil ${ }^{1}$
}

\author{
Maria do Socorro Pereira ${ }^{2,4}$ e Maria Regina de V. Barbosa ${ }^{3}$
}

Recebido em 3/04/2008. Aceito em 9/10/2008

RESUMO - (Uma nova espécie de Coussarea Aubl. (Rubiaceae) para a Mata Atlântica no Estado da Bahia, Brasil). Uma nova espécie, Coussarea andrei M.S. Pereira \& M.R. Barbosa, coletada em remanescentes de Mata Atlântica no Estado da Bahia, Brasil, é descrita e ilustrada. Próxima de Coussarea nodosa (Benth.) Müll. Arg., difere desta pelas folhas elípticas, pedúnculo da inflorescência com mais de $2,5 \mathrm{~cm}$ de comprimento, tirsos não umbeliformes, corola hipocrateriforme e o epicarpo do fruto de coloração castanho-dourado quando maduro.

Palavras-chave: Coussarea, Mata Atlântica, Rubiaceae

ABSTRACT - (A new species of Coussarea Aubl. (Rubiaceae) from the Atlantic Forest of Bahia State, Brazil). A new species, Coussarea andrei M.S. Pereira \& M.R. Barbosa, collected in Atlantic Forest remnants in Bahia, Brazil, is described and illustrated. It is close to Coussarea nodosa (Benth.) Müll. Arg., differing in the elliptical leaves, peduncle over $2.5 \mathrm{~cm}$ long, non-umbelliform thyrse, hypocrateriform corolla and epicarp golden-brownish when ripe.

Key words: Atlantic Forest, Coussarea, Rubiaceae

\section{Introdução}

O gênero Coussarea Aubl. compreende aproximadamente 115 espécies distribuídas exclusivamente na região Neotropical, desde o México até a Argentina (Andersson 1992; Delprete 2004; Taylor \& Steyermark 2004; Gomes 2003a; 2003b; 2007). No Brasil os dois centros de maior diversidade do gênero estão concentrados na Floresta Amazônica e na Mata Atlântica, com espécies endêmicas a estes Biomas.

Durante a revisão das espécies de Coussarea ocorrentes na Mata Atlântica, como parte da Tese de Doutorado (Pereira 2007), foi encontrado um novo táxon para a Mata Atlântica no Estado da Bahia, comumente identificado de maneira errônea em coleções como Coussarea bahiensis Müll. Arg., sendo aqui descrito como uma nova espécie.

\section{Material e métodos}

Foram analisados aproximadamente 2.000 espécimens entre exemplares-tipo, fotografias dos tipos, materiais históricos e recentes do gênero Coussarea provenientes de herbários nacionais e estrangeiros: ALCB, B, BHCB, BM, BR, C, CEN, CEPEC, EAC, EAN, F, FUEL, G, GUA, HB, HBR, HRB, HRCB, HUFU, IAC, ICN, INPA, IPA, JPB, K, M, MBM, MBML, MO, NY, P, PEUFR, R, RB, RFA, RUSU, SP, SPF, UB, UEC, UFP, VIC, W e WU.

A partir da análise desses materiais, procurando-se abranger a maior representatividade possível dentro do gênero, foram elaborados: a diagnose em latim, acompanhada da respectiva descrição e ilustração do novo táxon, apresentando-se ainda comentários taxonômicos e a distribuição geográfica da nova espécie no Estado da Bahia.

O epíteto específico é uma homenagem ao botânico André M. de Carvalho, pela grande contribuição ao estudo da Mata Atlântica Nordestina, em particular no Estado da Bahia.

\section{Resultados e discussão}

Coussarea andrei M.S. Pereira \& M.R. Barbosa, sp. nov. Tipo: BRASIL. Bahia: Município de Una, Reserva

\footnotetext{
Parte da Tese de Doutorado da primeira Autora

2 Universidade Federal de Pernambuco, Av. Prof. Moraes Rego s.n., Cidade Universitária, 50670-901 Recife, PE, Brasil

3 Universidade Federal da Paraíba, Departamento de Sistemática e Ecologia, C. Postal 5065, Cidade Universitária, 58051-970 João Pessoa, $\mathrm{PB}$, Brasil

4 Autor para correspondência: m.s_pereira@bol.com.br
} 
Biológica do Mico-leão, entrada no Km 46 da Rodovia BA-001 Ilhéus/Una, $15^{\circ} 09^{\prime} \mathrm{S}$ e $39^{\circ} 05^{\prime} \mathrm{W}, 28 / \mathrm{VI} /$ 1993, fl., A. M. de Carvalho et al. 4247 (Holótipo: CEPEC; Isótipo: ALCB, NY).

Fig. 1

Species nova $C$. nodosa affini sed elliptica folia, thyrsus non umbeliformis, corollae hypocrateriformis et fructus lucidus differt.

Árvore 2,5-7 m alt. Ramos estriados, comprimidos, castanho-esverdeados a castanho-acinzentados quando secos, glabros; entrenós 5-15 cm compr., nós dilatados. Estípulas persistentes, 2-5×5-10 mm, triangulares, ápice agudo a arredondado, esverdeadas a castanhas, glabras. Lâmina foliar 14-30×6-13 cm, elíptica, ápice agudo a acuminado, base aguda, margem inteira, plana ou recurvada, cartácea a coriácea, castanha a nigrescente quando seca, glabra em ambas as faces, pecíolo 1-3×0,2-0,5 cm, estriado, não verruculoso, castanhoesverdeado, glabro; nervura principal proeminente, robusta, estriada na face abaxial, glabra; nervuras secundárias 6-10/lado, ascendentes, sem domácias. Tirsos terminais, paucifloros, $3-4 \times 3,5-4,5 \mathrm{~cm}$, 10-12-(14-18) flores; pedúnculo 3,5-5×0,2-0,3 cm, castanho-esverdeado, glabro. Botões florais tetrágonos, oblongos, robustos, com ápice agudo; pedicelo $2-3 \mathrm{~mm}$ compr., glabro; hipanto obcônico, 1-3×1-1,5 mm, glabrescente. Cálice 1-6×2-5 mm, esverdeado, truncado, raro curtamente 4-denticulado, dentículos desiguais, persistente, glabro, glandulígero internamente. Corola hipocrateriforme, branca, tetrâmera, tubo 7-10×1-2 mm, glabro, lobos 3-4(5) $\times 1-2 \mathrm{~mm}$, triangulares a lanceolados, carnosos, apiculados, glabros. Estames 4 , inclusos ou exsertos, inseridos na região mediana do tubo da corola; filetes 1-1,5 mm compr., glabros; anteras 4-6×0,2-0,5 mm, lineares, dorsifixas na região mediana, agudas no ápice e arredondadas na base, esbranquiçadas. Ovário bilocular, uniovular, septo delgado, óvulo de inserção basal, ereto, disco nectarífero inteiro; estilete terminal, incluso ou exserto, 5-7 mm compr., glabro, bífido, ramos 2-3 mm compr., glabros. Frutos drupáceos, 1,5-2,5×1-1,5 cm elípticos a oblongos, castanho-dourados, com brilho intenso, glabros.

Parátipos: BRASIL. Bahia: Jequié, Fazenda Brejo Novo, a 10,5 km da Av. Otávio Mangabeira, $13^{\circ} 56^{\prime} 41,4$ "S; $040^{\circ} 06^{\prime} 33,9$ 'W, 617 a $750 \mathrm{~m}$, 13/IX/2003, fr., G. E. L. Macedo \& M. F. Souza 280 (PEUFR); 1356'50,9”'S; 04006'33,9”W, 635 m, 19/VIII/2004, fr., G. E. L. Macedo 1235 (PEUFR). Ilhéus, Estrada entre Sururú e Vila Brasil, a 6-14 Km de Sururú, a 12-20 km ao SE de Buerarema, 10/XI/1979, fl., S.A. Mori \& F. Benton s.n. (CEPEC). Itabuna, Fazenda S. Rafael Una da Mata, 8/IX/1971, fl., fr., R.S. Pinheiro 1613 (CEPEC). Una, Reserva Biológica do
Mico-leão (IBAMA), km 46 da Rodovia BA-001 Ilhéus/Una, $15^{\circ} 09^{\prime}$ S e $39^{\circ} 05^{\prime} \mathrm{W}, 27 / \mathrm{VII} / 1993$, fr., A.M. de Carvalho et al. 4288 (CEPEC); 15 10'50"'s, 39॰03'40”'W, 6/II/1994, fr., W. W. Thomas et al. 10.322 (CEPEC, NY); $15^{\circ} 09^{\prime}$ 'S e $39^{\circ} 05^{\prime} \mathrm{W}, 30 / \mathrm{VIII} / 1995$, fr., A. M. de Carvalho et al. 6070 (ALCB, CEPEC); $15^{\circ} 09^{\prime} \mathrm{S}$ e $39^{\circ} 05^{\prime} \mathrm{W}, 12 / \mathrm{X} / 1995$, fr., A.M. Amorim et al. 1725 (ALCB, CEPEC); $15^{\circ} 09^{\prime}$ 'S e $39^{\circ} 05 \mathrm{~W}, 28 / \mathrm{I} / 1998$, fl., A.M. de Carvalho et al. 6486 (CEPEC); 1509'S e $39^{\circ} 05^{\prime} \mathrm{W}, 19 / \mathrm{III} / 1998$, fr., J.G. Jardim et al. 1711 (CEPEC); $15^{\circ} 09^{\prime}$ 'S e $39^{\circ} 05^{\prime} \mathrm{W}, 22 / \mathrm{VII} / 1998$, fr., J.G. Jardim et al. 1815 (CEPEC).

A espécie ocorre em remanescentes de Mata Atlântica no Estado da Bahia, nos municípios de Una, Ilhéus, Itabuna, e também no município de Jequié. Foi coletada com flores nos meses de janeiro, setembro e novembro, e com frutos nos meses de fevereiro e março e de julho a outubro.

Pode ser facilmente reconhecida em virtude dos frutos quando maduros, apresentarem uma coloração castanho-dourado com brilho intenso (lustrosos), característica não encontrada nas demais espécies do gênero Coussarea Aubl. É próxima de Coussarea nodosa (Benth.) Müll. Arg., mas difere desta pelas folhas elípticas, pedúnculo da inflorescência com mais de $2,5 \mathrm{~cm}$ de comprimento, tirsos não umbeliformes, corola hipocrateriforme e pela coloração castanho-dourado do fruto quando maduro. Coussarea nodosa (Benth.) Müll. Arg., apresenta folhas lanceoladas a oblongolanceloladas, pedúnculo da inflorescência com até $2,5 \mathrm{~cm}$ de comprimento, tirsos umbeliformes, corola infundibuliforme a tubulosa e o fruto quando maduro de coloração amarelada, sem brilho (opaco). Difere de Coussarea bahiensis Müll. Arg. por esta última apresentar ramos com nós não dilatados, estípulas caducas, inflorescência multifloras, flores com comprimento 2 vezes maiores que as do novo táxon, e frutos amarelos quando maduros.

\section{Agradecimentos}

Agradecemos ao Programa da Margaret Mee Fellowship, do Royal Botanic Gardens, Kew, UK, pelo apoio e viabilização para visita da primeira autora ao Herbário do Royal Botanic Gardens, Kew (K) e demais Herbários Europeus, e ao Conselho Nacional de Desenvolvimento Científico e Tecnológico do Brasil (CNPq) pelo financiamento, através das bolsas concedidas a ambas as autoras durante o desenvolvimento de parte deste trabalho. Agradecemos também aos curadores e pesquisadores dos Herbários CEPEC e ALCB pelo empréstimo dos espécimens citados, e ao botânico Edgley César (K) pelo Abstract. 


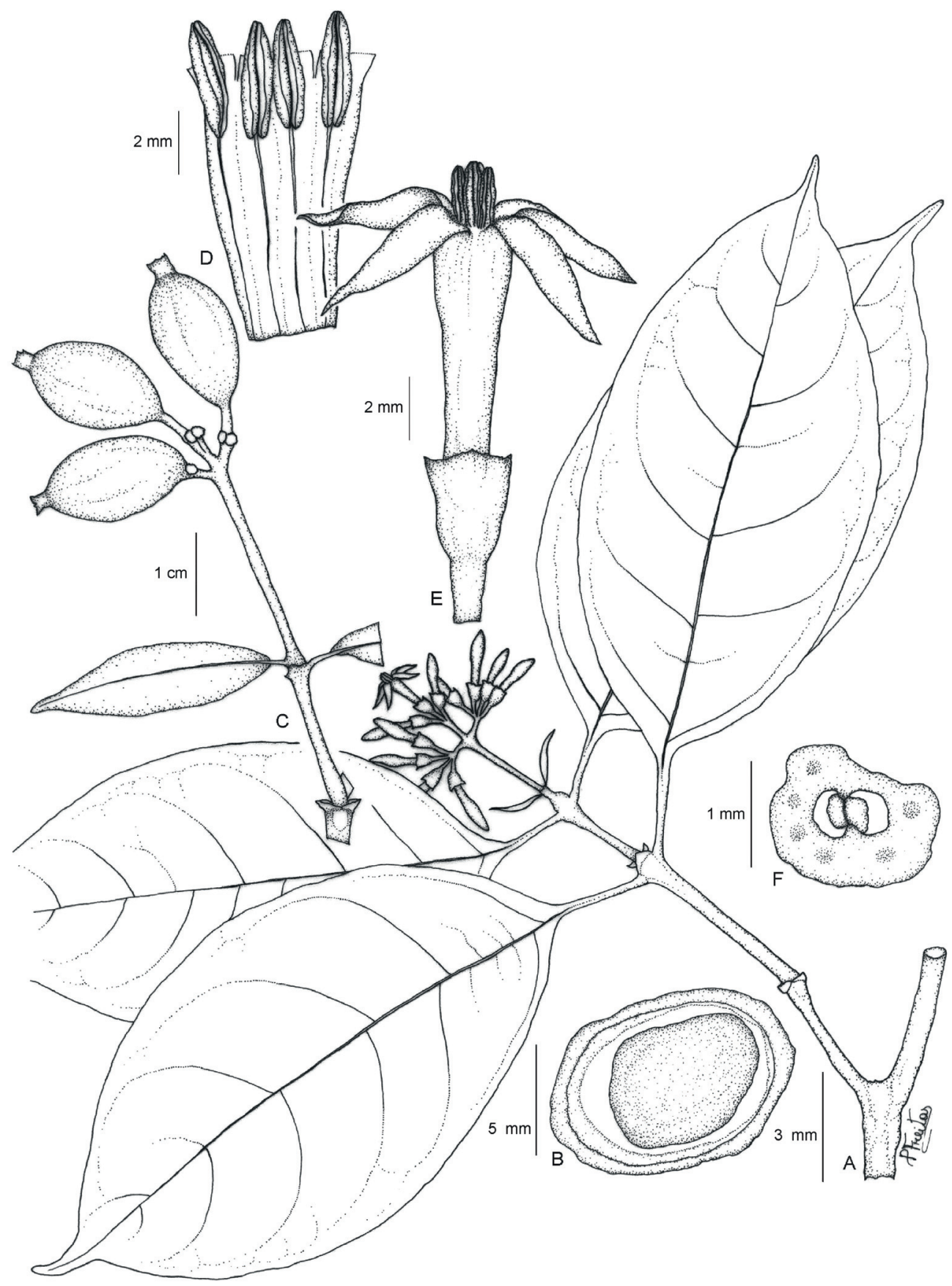

Figura 1. Coussarea andrei M.S. Pereira \& M.R. Barbosa (A.M. de Carvalho et al. 4247). A. Ramo florido. B. Semente. C. Ramo frutífero. D. Corola dissecada. E. Flor. F. Secção transversal do ovário.

\section{Referências bibliográficas}

Andersson, L. 1992. A provisional checklist of neotropical Rubiaceae. Scripta Botanica Belgica 1: 1-199.

Delprete, P.G. 2004. Rubiaceae. Pp. 328-333. In: N. Smith; S.A Mori; A. Henderson; D. Wm. Stevenson \& S.V. Heald. Flowering plants of the neotropics. Princeton and Oxford, New Jersey, The New York Botanical Garden. Princeton University Press.

Gomes, M. 2003a. Novas espécies de Coussarea Aubl. e Faramea Aubl. (Rubiaceae, tribo Coussareae). Acta Botanica Brasilica 17: $439-448$.
Gomes, M. 2003b. Reavaliação taxonômica de algumas espécies dos gêneros Coussarea Aubl. e Faramea Aubl. (Rubiaceae, tribo Coussareae). Acta Botanica Brasilica 17: 449-466.

Gomes, M. 2007. Coussarea Aubl. Pp. 299-306. In: S.L. JungMendaçolli. Rubiaceae. Flora Fanerogâmica do Estado de São Paulo. v.5. Instituto de Botânica, São Paulo.

Pereira, M.S. 2007. O genêro Coussarea Aubl. (Rubiaceae, Rubioideae, Coussareae) na Mata Atlântica. Tese de Doutorado, Recife, Universidade Federal de Pernambuco.

Taylor, C.M. \& Steyermark, J.A. 2004. Coussarea Aubl. Flora of the Venezuelan Guayana 8: 562-567.

Versão eletrônica do artigo em www.scielo.br/abb e http://www.botanica.org.br/acta/ojs 